\title{
Effect of Solution Treatment on the Hardness and Tensile Properties of Al-Mg-Si Alloys for Automotive Chassis
}

\author{
Bo-Ra Jin, Dong-Woog Ha and Chang-Yeol Jeong* \\ Departments of Nuclear and Energy System Engineering, Dongguk University, 123 Dongdae-ro, Gyeongju-si, 38066, Republic of Korea
}

Al-Mg-Si alloys, which are used mainly as wrought materials, can also be used as casting materials because of the development of casting technologies. To improve the mechanical properties of alloys, the casting materials are often subjected to different heat treatments. Therefore, the influence of heat treatment on the mechanical properties of aluminum alloys needs to be understood before wrought alloys can be used in automotive casting components. This study examined the effects of solution treatment on the microstructure and mechanical properties of casting $\mathrm{Al}-\mathrm{Mg}-\mathrm{Si}$ alloy for automotive chassis. After a solution treatment for 5 and $8 \mathrm{~h}$ at 535 to $565^{\circ} \mathrm{C}$, the microstructures were examined depending on the heat treatment temperature and time by optical microscopy, scanning electron microscopy, energy dispersive X-ray spectroscopy, and X-ray diffraction. As a result, $\mathrm{Al}$ matrix, $\beta-\mathrm{Al}_{5} \mathrm{FeSi}$ and $\mathrm{Mg}_{2} \mathrm{Si}$ phases were observed in solution-treated $\mathrm{Al}-\mathrm{Mg}-\mathrm{Si}$ alloys. In addition, the solution treatment temperature and time had a significant effect on the hardness and tensile properties of the alloy. The hardness and tensile strength increased with increasing solution treatment temperature to $555^{\circ} \mathrm{C}$ due to the solid solution hardening with the dissolution of residual phases. In contrast, when the solution temperature increased further to $565^{\circ} \mathrm{C}$ and the solution treatment time was increased, the hardness and the tensile strength decreased due to softening by grain growth rather than the effects of the solid solution hardening. In addition, the uniformity of the mechanical properties by each location of the specimen increased with increasing solution treatment duration due to the increase in time needed to produce a sufficient solid solution. [doi:10.2320/matertrans.M2018368]

(Received November 26, 2018; Accepted February 6, 2019; Published April 5, 2019)

Keywords: Al-Mg-Si alloy, automobile, solution treatment, hardness, tensile strength

\section{Introduction}

In recent years, the weight of vehicles has been increasing due to the increasing number of parts for improving the crashworthiness and convenience performance of the vehicle. On the other hand, the increased weight of the vehicle means that the exhaust gas and fuel efficiency regulations cannot be satisfied. Hence, there is increasing demand for the weight reduction of cars. Therefore, replacing existing materials with lighter materials, such as aluminum and magnesium alloys, is the most efficient method for reducing the weight of vehicles. ${ }^{1-4)}$ Aluminum alloys have been used steadily in the automotive industry owing to their excellent specific strength and relatively low $\operatorname{cost}^{2,5-7)}$ but existing aluminum alloys have lower strength than currently used automotive steel, highlighting the need for further research to improve the mechanical properties of cast alloys. To improve the strength of aluminum alloys, the grain refinement, ${ }^{8-10)}$ precipitation strengthening heat treatment, $6,7,11)$ and research on the adjustment of alloying element ${ }^{12,13)}$ are currently under study. In addition, a study on the improvement of aluminum casting alloys with relatively lower strength than wrought alloys owing to internal casting defects and large grain size has attracted considerable interest. Although studies have been conducted to manufacture castings using wrought alloys with excellent mechanical properties, wrought alloys have higher melting temperatures than casting alloys during casting and lower fluidity of the molten metal, as well as a larger number of casting defects, which reduce the mechanical properties. ${ }^{14-17)}$ To improve the castability of the wrought aluminum alloys, research on casting technology to reduce casting defects, such as the squeeze casting, and modifications of alloying elements, such as $\mathrm{Si}, \mathrm{Mg}$, and $\mathrm{Cu}$, are being carried out. ${ }^{15-17)}$ On the other hand, there have been fewer systematic

*Corresponding author, E-mail: jcy@dongguk.ac.kr studies of various strengthening methods by heat treatment after casting the parts applied the wrought alloys. This study examined the effects of heat treatment on the mechanical properties of a rear carrier fabricated by the improvement of Al-Mg-Si wrought alloys used for automobile chassis. The optimal heat treatments were then investigated. The behavior of the microstructure, hardness, and tensile properties depending on the solution treatment temperature and time conditions were analyzed and the influence of heat treatment factors was evaluated quantitatively.

\section{Experimental}

Table 1 lists the chemical composition of the aluminum alloy, which was based on A16061, as used in wrought material; $\mathrm{Zr}$ was added for grain refinement and the $\mathrm{Si}$ content was increased to improve castability. In addition, the $\mathrm{Zn}$ contents which can accelerate the nucleation of precipitates were increased to improve the strength through precipitation hardening. ${ }^{18,19)}$ To compare the effects of heat treatment depending on the position of the automotive component, the rear carriers, as shown in Fig. 1, were cast using the vacuum-assisted low pressure die-cast method. The specimens were divided into \#1, \#2, \#3 and \#4, and each specimen was cut in half and heat treated to evaluate the microstructure, hardness, and tensile properties.

Figure 2 shows the heat treatment process of the alloys. After the internal temperature of the electric furnace as same mass production conditions was stabilized at the set temperature, the specimens were heat treated to maintain the heat treatment time, including the temperature rise time. The solution treatment was conducted over the temperature range, $535 \sim 565^{\circ} \mathrm{C}$, at $10^{\circ} \mathrm{C}$ intervals, and the solution treated time was maintained for 5 and $8 \mathrm{~h}$ respectively. The specimens were then cooled for 10 minutes in the water bath at $40^{\circ} \mathrm{C}$. The hardness was measured at least 10 times depending on 
Table 1 Chemical compositions of the Al-Mg-Si alloy (mass\%).

\begin{tabular}{lcccccccccc}
\hline & $\mathrm{Cu}$ & $\mathrm{Si}$ & $\mathrm{Mg}$ & $\mathrm{Fe}$ & $\mathrm{Mn}$ & $\mathrm{Ti}$ & $\mathrm{Zn}$ & $\mathrm{Cr}$ & $\mathrm{Zr}$ & $\mathrm{Al}$ \\
\hline Alloy & 0.3 & 1.0 & 0.7 & 0.1 & 0.07 & 0.13 & 0.7 & 0.08 & 0.12 & Rem \\
\hline
\end{tabular}

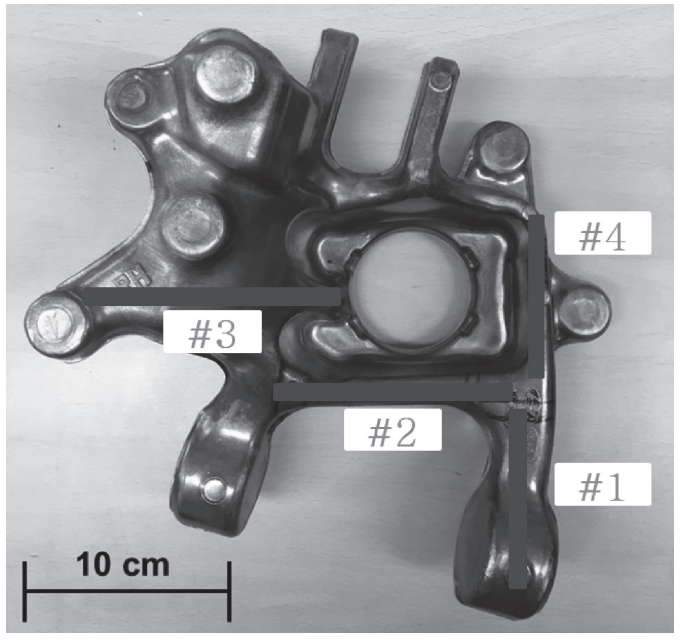

Fig. 1 Al-Mg-Si alloy component and parts of the component.

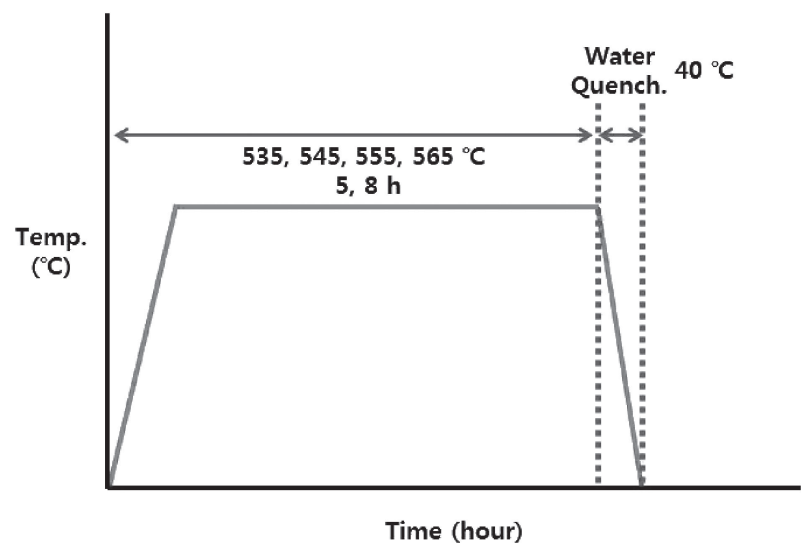

Fig. 2 Heat treatment processes of the Al-Mg-Si alloy.

the specimen size using a Rockwell hardness tester (model CV-600MA) at room temperature under a load for 5 seconds with a B scale (HRB). After the average of hardness was calculated excluding the maximum and minimum values, they were converted to the Brinell hardness (HB, 10/500/15) value using the conversion formula of ASTM E140. ${ }^{20)}$ The tensile tests were carried out at a strain rate of $1 \mathrm{~mm} / \mathrm{min}$ at room temperature using a universal testing machine (model Instron 8861). Under the same heat treatment conditions, tensile tests were conducted twice in the \#1 position, and were conducted once in \#2 to \#4. Tensile specimens were fabricated into cylindrical sub-size rods with a gauge length of $16 \mathrm{~mm}$ and a diameter of $4 \mathrm{~mm}$ according to ASTM $\mathrm{E} 8 \mathrm{M},{ }^{21)}$ as shown in Fig. 3. The volume fraction of residual phases at the \#4 sites and the grain size at the \#3 sites were measured by optical microscopy (OM, model Nikon ECLIPSE MA100) and an image analysis program (model IMT iSolution DT). To observe grain size with the heat treatment conditions, the specimens were etched for 2 minutes in a solution prepared from $95 \mathrm{ml}$ of water, $10 \mathrm{ml}$ of sulfuric acid and $5 \mathrm{ml}$ of hydrofluoric acid. The residual phases and precipitates of the alloy were analyzed by scanning electron microscopy (SEM, model SU8010) and energy dispersive X-ray spectroscopy (EDS, model X-max 50) and X-ray diffraction (XRD, model D/MAX-2500).

\section{Results and Discussion}

\subsection{Microstructure}

Figure 4 shows the microstructure of the $\mathrm{Al}-\mathrm{Mg}-\mathrm{Si}$ alloy depending on the solution treatment temperature and time. As shown in Figs. $4(\mathrm{a}) \sim(\mathrm{g})$, which are the samples after a $5 \mathrm{~h}$ solution treatment and Figs. $4(\mathrm{~b}) \sim(\mathrm{h})$, which are after $8 \mathrm{~h}$, the amount of the residual phase decreased with increasing solution treatment temperature for the same solution treatment time. In addition, the residual phase decreased with increasing solution treatment time at the same solution treatment temperature, which is consistent with the behavior due to the increase in temperature. For quantitative analysis, 10 or more images were taken at $\times 200$ magnification from the center of the \#4 site by OM. The area fraction of the residual phases for each solution treatment conditions was then measured under the same threshold conditions using the area fraction measurement tool of the image analyzer. On the other hand, if the image is a random specimen for a constant structure, the area fraction of the structure is equal to the

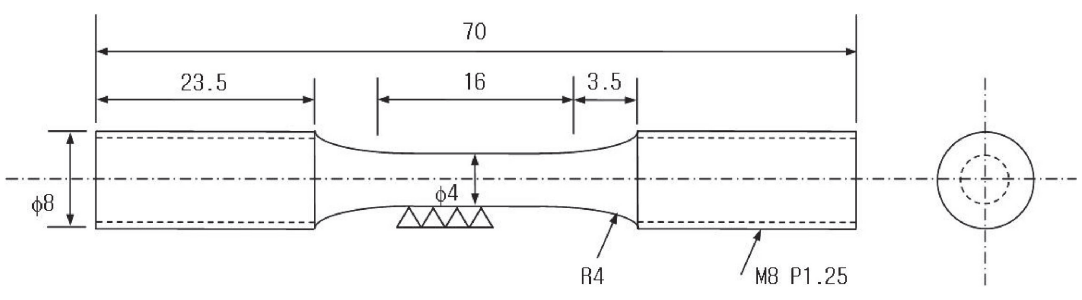

Unit: mm

Fig. 3 Shape of tensile test specimen (ASTM E8M). 


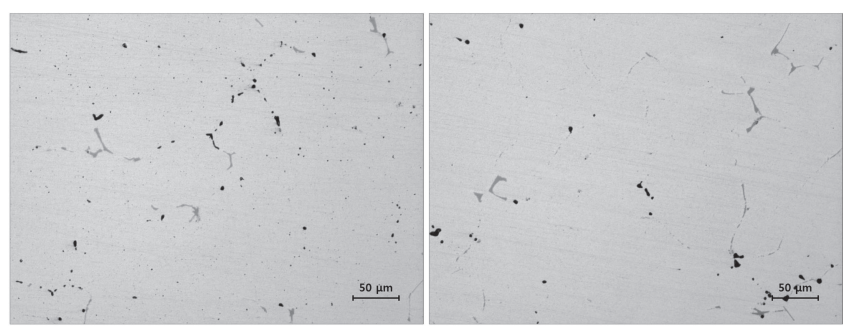

(a)

(b)

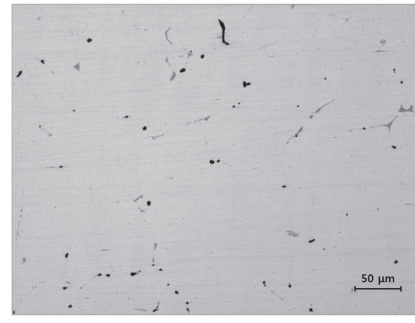

(c)

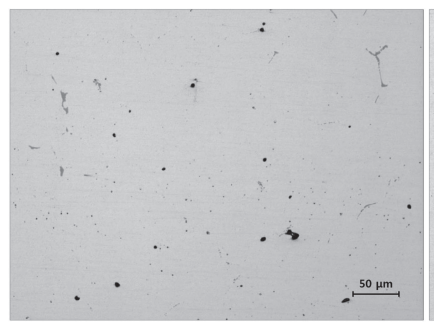

(e)

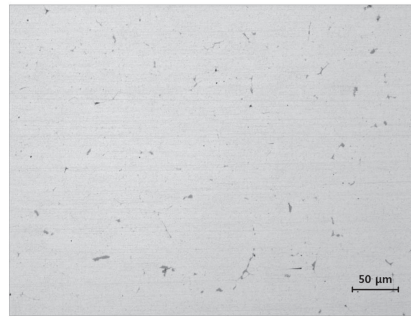

(g)

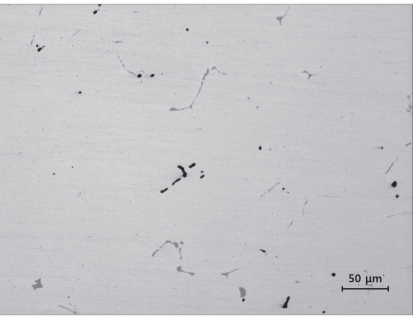

(d)

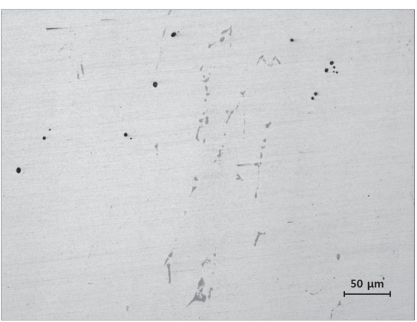

(f)

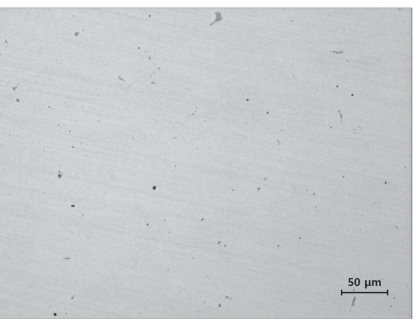

(h)

Fig. 4 Residual phases of the $\mathrm{Al}-\mathrm{Mg}-\mathrm{Si}$ alloy after solution treatment: (a) $535^{\circ} \mathrm{C}, 5 \mathrm{~h}$; (b) $535^{\circ} \mathrm{C}, 8 \mathrm{~h}$; (c) $545^{\circ} \mathrm{C}, 5 \mathrm{~h}$; (d) $545^{\circ} \mathrm{C}, 8 \mathrm{~h}$; (e) $555^{\circ} \mathrm{C}$, $5 \mathrm{~h}$; (f) $555^{\circ} \mathrm{C}, 8 \mathrm{~h}$; (g) $565^{\circ} \mathrm{C}, 5 \mathrm{~h}$; and (h) $565^{\circ} \mathrm{C}, 8 \mathrm{~h}$.

volume fraction. ${ }^{22)}$ Figure 5 shows the average volume fraction of the residual phases according to the solution treatment conditions. Similar to that shown in Fig. 4, the volume fraction of the residual phases of the Al-Mg-Si alloy decreased with increasing solution temperature and time, which was attributed to the increase in solubility of the solute atoms constituting the residual phase. The additional analysis for the residual phases was carried out and the results are as follows:

The specimens that were solution treated at $535^{\circ} \mathrm{C}$ for $5 \mathrm{~h}$ were analyzed by SEM and EDS to confirm the composition of the residual phases observed in Fig. 4, as shown in Fig. 6. Figure 6(a) shows SEM image of the residual phases of $\mathrm{Al}-\mathrm{Mg}-\mathrm{Si}$ alloy after solution treatment. It consisted of precipitated phases A, B and matrix C. Figures $6(\mathrm{~b}) \sim(\mathrm{d})$ show the composition of each phase analyzed by EDS. The

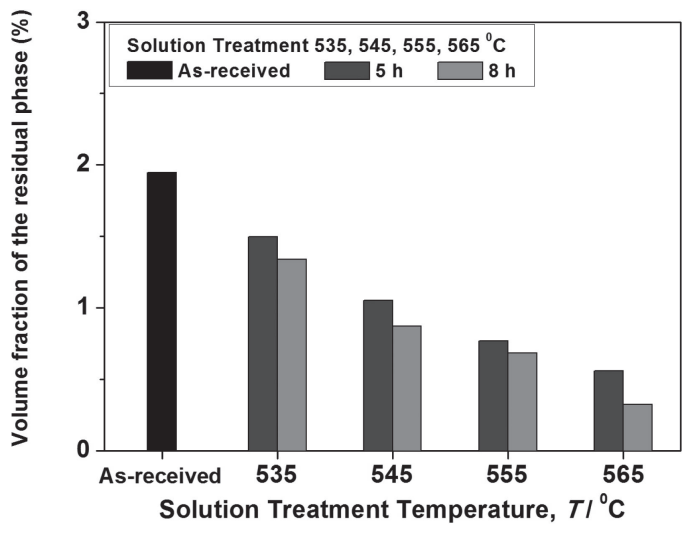

Fig. 5 Volume fractions of the residual phases on the Al-Mg-Si alloy after solution treatment.

residual phases were analyzed through the elements corresponding to each peak and their ratios. As a result, A and $\mathrm{B}$ are regarded as $\beta-\mathrm{Al}_{5} \mathrm{FeSi}$ and $\mathrm{Mg}_{2} \mathrm{Si}$ respectively, and the composition of the matrix $\mathrm{C}$ is similar to the composition of the aluminum alloy. The $\beta$-phase reduces tensile strength and elongation; ${ }^{23)}$ hence, a decrease in the residual $\beta$ phase through a solution treatment is required. Optimization of the solution treatment temperature and time is required for sufficient redissolution of the residual phases because the volume fraction of the residual phases decreases with increasing solution treatment temperature and time. The A356 alloy, which is used widely as cast aluminum alloy, is composed of a pro-eutectic phase of $\alpha-\mathrm{Al}$ and a eutectic phases of $\mathrm{Al}-\mathrm{Si}, \beta-\mathrm{Al}_{5} \mathrm{FeSi}, \mathrm{Mg}_{2} \mathrm{Si}$, and $\pi-\mathrm{Al}_{8} \mathrm{FeMg}_{3} \mathrm{Si}_{6}{ }^{13,23)}$

Figure 7 shows the distribution of each element in the $\mathrm{Al}-\mathrm{Mg}-\mathrm{Si}$ alloy solution treated at $535^{\circ} \mathrm{C}$ for $5 \mathrm{~h}$ using EDSmapping. The location, which has low density of $\mathrm{Al}$, and location of residual phase coincided. In the $\beta$ phase, the ratio of $\mathrm{Si}$ and $\mathrm{Fe}$ is high and the density of $\mathrm{Si}$ and $\mathrm{Mg}$ is high in $\mathrm{Mg}_{2} \mathrm{Si}$. In the matrix, the proportion of $\mathrm{Al}$ is high and the alloy elements are distributed uniformly. These are consistent with the results of the composition analysis of particles A, B and $\mathrm{C}$ as shown in Fig. 6.

XRD was carried out to quantitatively analyze the types of residual phases and volume fraction changes with heat treatment conditions analyzed previously by OM and EDS and the results are shown in Fig. 8. The Al-Mg-Si alloy consisted of $\mathrm{Mg}_{2} \mathrm{Si}, \beta-\mathrm{Al}_{5} \mathrm{FeSi}$, and some $\mathrm{MgZn}_{2}$ phase and matrix, and the amount of each phase changed according to the heat treatment conditions. When the specimens were solution treated, the amount of $\mathrm{Mg}_{2} \mathrm{Si}, \beta-\mathrm{Al}_{5} \mathrm{FeSi}$, and $\mathrm{MgZn}_{2}$ phase tended to decrease compared to the as-received specimens after casting. In particular, in the as-received specimens, a peak for $\mathrm{Mg}_{2} \mathrm{Si}$ was observed at $40^{\circ} 2 \theta$, but the peak decreased after solution treatment. The residual phases tended to decrease with increasing solution treatment temperature at a given solution treatment time and also the solution treated time increased at the same solution treatment temperature. These are consistent with the results of OM and EDS analysis depending on the solution treatment conditions, as shown in Figs. $4 \sim 6$. On the other hand, $\beta-\mathrm{Al}_{5} \mathrm{FeSi}$ appears to increase after solution treatment because the results overlapped with the $\beta-\mathrm{Al}_{5} \mathrm{FeSi}$ and $\mathrm{Al}_{95} \mathrm{Fe}_{4} \mathrm{Cr}$ phase. When 


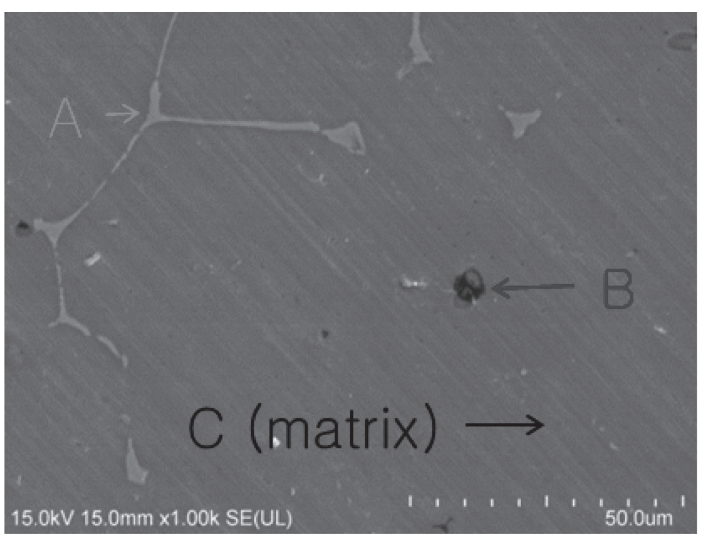

(a)

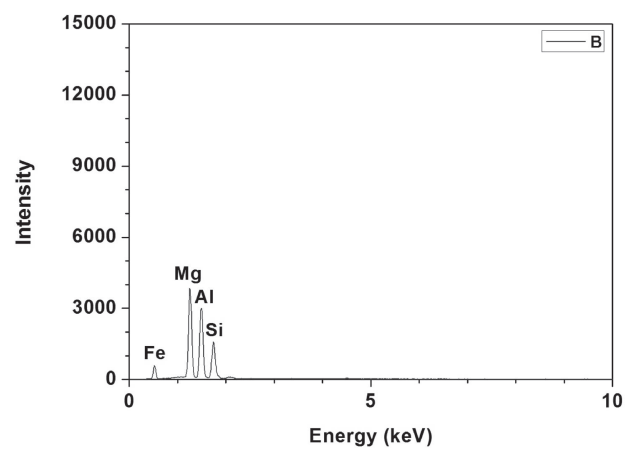

(c)

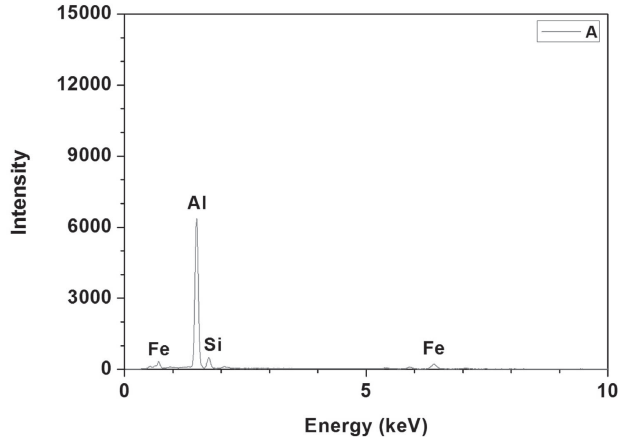

(b)

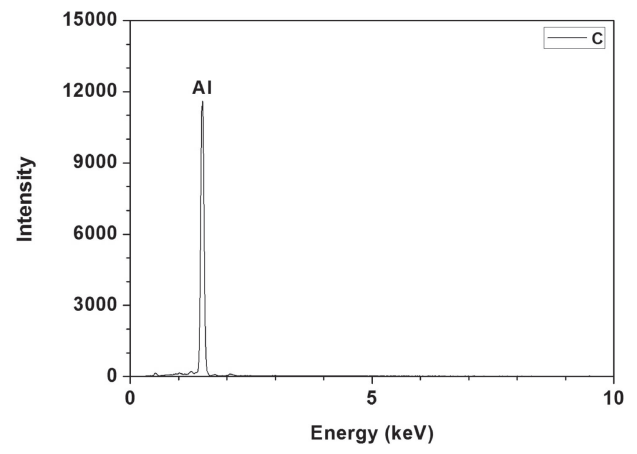

(d)

Fig. 6 SEM images and EDS of the Al-Mg-Si alloy after solution treatment at $535^{\circ} \mathrm{C}$ and $5 \mathrm{~h}$, (a) $\times 1000$, (b) EDS of the A phase in Figs. 6(a), (c) EDS of the B phase in Figs. 6(a) and (d) EDS of the C phase in Figs. 6(a).

the effect of the $\mathrm{Al}_{95} \mathrm{Fe}_{4} \mathrm{Cr}$ phase was removed from the overlapped results, the $\beta$ - $\mathrm{Al}_{5} \mathrm{FeSi}$ phase would result in a decrease. Although the $\mathrm{Al}_{95} \mathrm{Fe}_{4} \mathrm{Cr}$ phase formed after heat treatment for aluminum alloys, ${ }^{24,25)}$ the effects of the $\mathrm{Al}_{95} \mathrm{Fe}_{4} \mathrm{Cr}$ phase on the mechanical properties is not yet known and further studies will be required.

Solute atoms dissolved into the $\mathrm{Al}$ matrix after the solution treatment and the lattice constant changed due to lattice deformation. In addition, the solubility of solute atoms could be compared by calculating the lattice constant and generally, a larger lattice constant caused by the greater the distortion of the lattice causes an increase in strength. ${ }^{26)}$ In this study, the lattice constants with the heat treatment conditions were analyzed using previous XRD analysis and the results are shown in Fig. 9. The lattice constant increased with increasing solution treatment temperature after a $5 \mathrm{~h}$ solution time, which was caused by the increase in solid solution due to decomposition of the residual phases. ${ }^{26)}$ On the other hand, at the solution treatment temperature of $565^{\circ} \mathrm{C}$, the lattice constant decreased because it was unable to maintain the solid properties close to the melting temperature of the alloy. In addition, as the solution treatment time increased from 5 to $8 \mathrm{~h}$, the lattice constant decreased over the temperature range of $545 \sim 565^{\circ} \mathrm{C}$. The lattice constant decreased with increasing new precipitation phase, such as $\mathrm{Al}_{95} \mathrm{Fe}_{4} \mathrm{Cr}$, in addition to the solubility of residual phases, as shown in the previous XRD results. The lattice constant increased with increasing solution treatment time at $535^{\circ} \mathrm{C}$, which means that $535^{\circ} \mathrm{C}$ is insufficient for the solubility of the residual phase, and a heat treatment time of $5 \mathrm{~h}$ is not enough to complete the solute solubility, resulting in an increase in the lattice constant. Based on the experimental results of Fig. 9, it is expected that the maximum strength would be exhibited in the solution treated at $555^{\circ} \mathrm{C}$ for $5 \mathrm{~h}$. To determine the optimal heat treatment condition, the hardness and tensile properties of each solution treatment condition were evaluated and the results are as follows:

\subsection{Hardness}

To observe the changes in hardness depending on the solution treatment conditions and the position of the specimen, the HRB values as the B scale were measured using a Rockwell hardness tester and converted to HB, which is the Brinell hardness value, as shown in Fig. 10. Figure 10(a) shows that the hardness increased up to $555^{\circ} \mathrm{C}$ and decreases at $565^{\circ} \mathrm{C}$ for a $5 \mathrm{~h}$ solution treatment time. In addition, the tendency of the $8 \mathrm{~h}$ solution treatment time showed similar behavior to that of $5 \mathrm{~h}$, as shown in Fig. 10(b). Compared to Figs. 10(a) and (b), as the solution treat time was increased from 5 to $8 \mathrm{~h}$, the difference in hardness with each location of the specimen decreased due to the uniform solubilization of solute atoms with a sufficient heat treatment time. Figure 10(c) shows the mean hardness depending on the solution treatment conditions by each location of the specimens. Under the same solution treatment time conditions, the hardness increased with increasing solution treatment temperature up to $555^{\circ} \mathrm{C}$, but decreased at $565^{\circ} \mathrm{C}$. In addition, the hardness decreased with increasing 


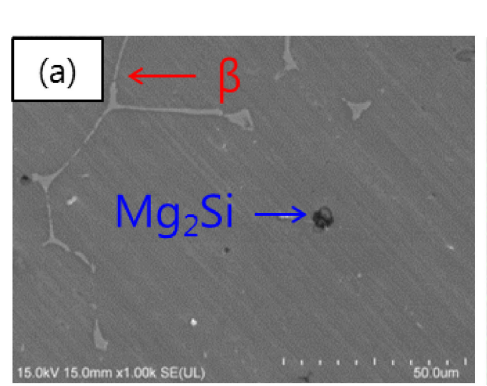

Mg Ka1_2

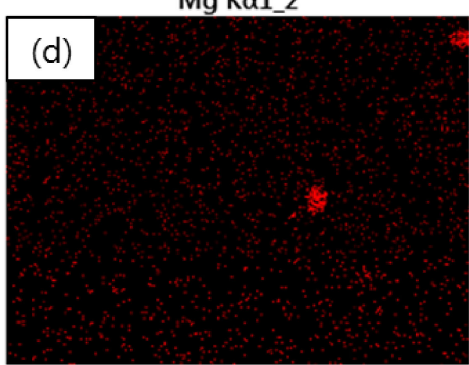

$\mathrm{Mn} K \alpha 1$

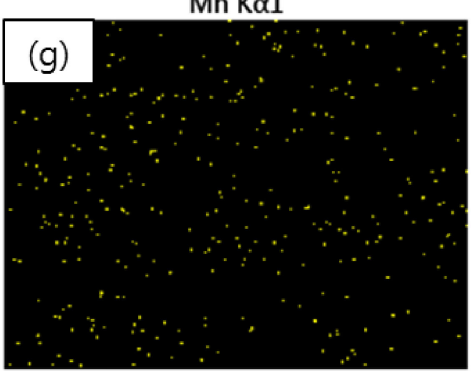

Ti K $\alpha 1$

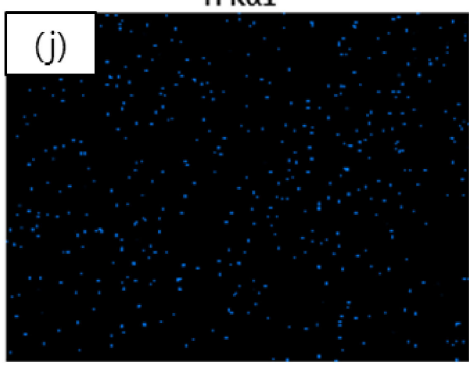

Al K $\alpha 1$

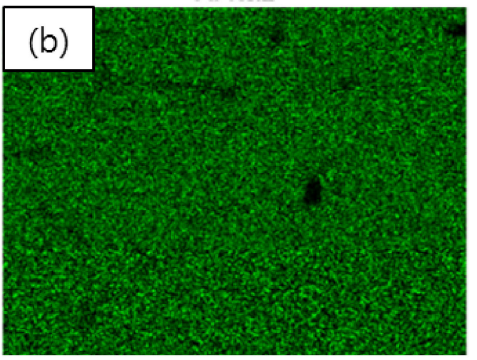

Fe K $\alpha 1$

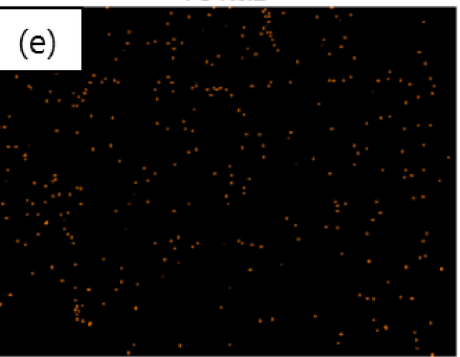

Cu La1_2

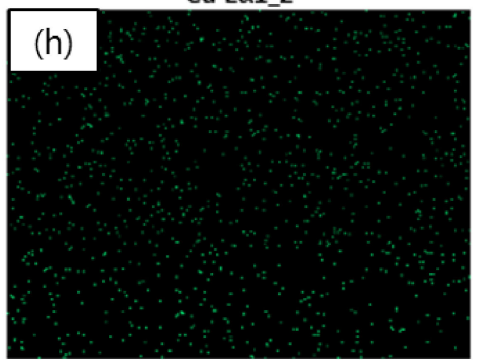

Zr L $\alpha 1$

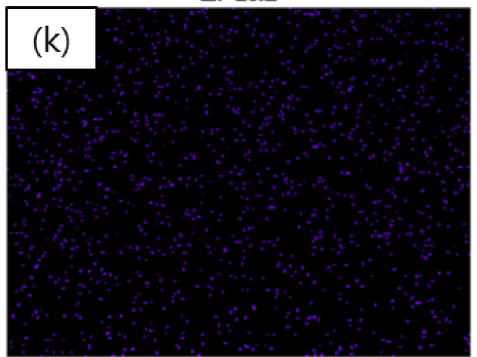

Si K $\alpha 1$

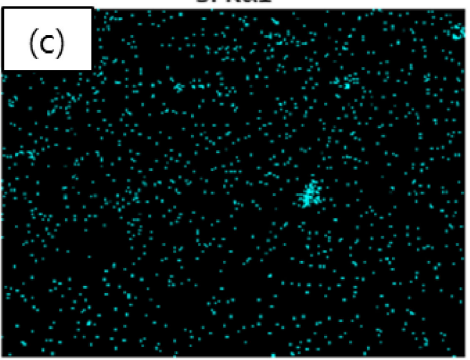

Zn L $\alpha 1 \_2$

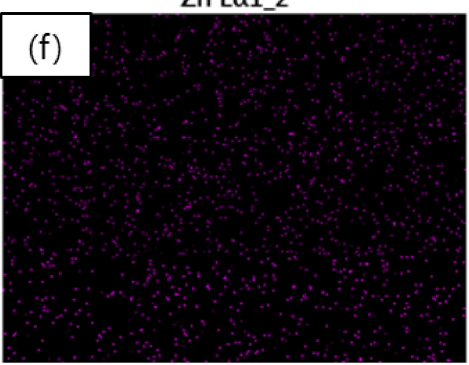

$\mathrm{Cr} \mathrm{K} \alpha 1$

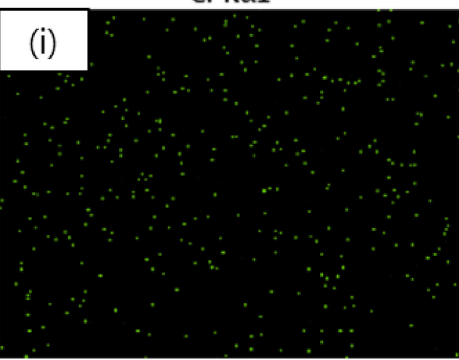

(i)

Fig. 7 SEM image and corresponding elemental distribution of the $\mathrm{Al}-\mathrm{Mg}-\mathrm{Si}$ alloy after solution treatment at $535^{\circ} \mathrm{C}$ and $5 \mathrm{~h}$, (a) SEM image, (b) $\mathrm{Al}$, (c) $\mathrm{Si}$, (d) $\mathrm{Mg}$, (e) Fe, (f) $\mathrm{Zn}$, (g) $\mathrm{Mn}$, (h) $\mathrm{Cu}$, (i) $\mathrm{Cr}$, (j) $\mathrm{Ti}$ and (k) $\mathrm{Zr}$.

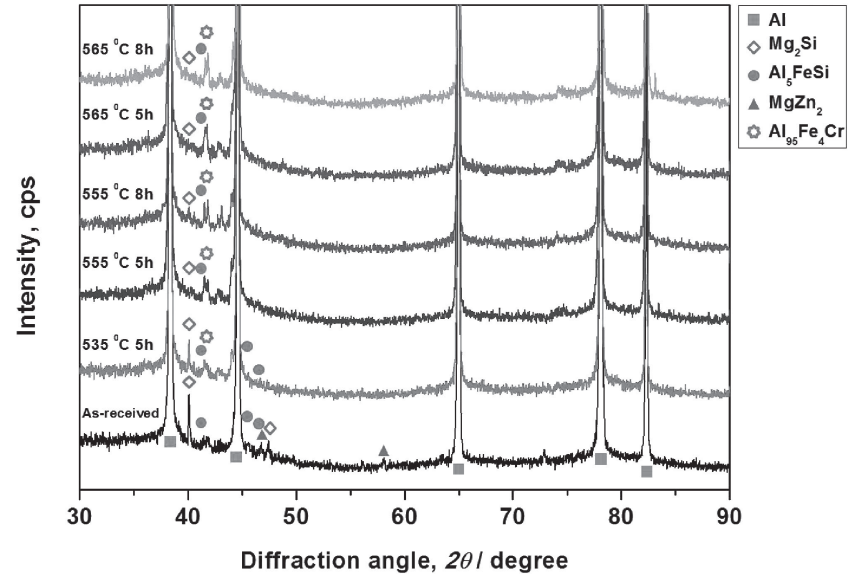

Fig. 8 XRD pattern of Al-Mg-Si alloy with solution treatment.

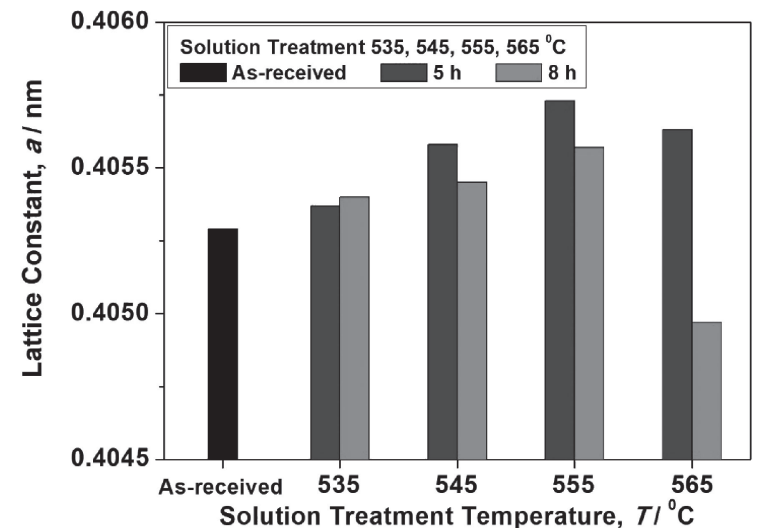

Fig. 9 Lattice parameter of the $\mathrm{Al}-\mathrm{Mg}-\mathrm{Si}$ alloy with solution treatment. 

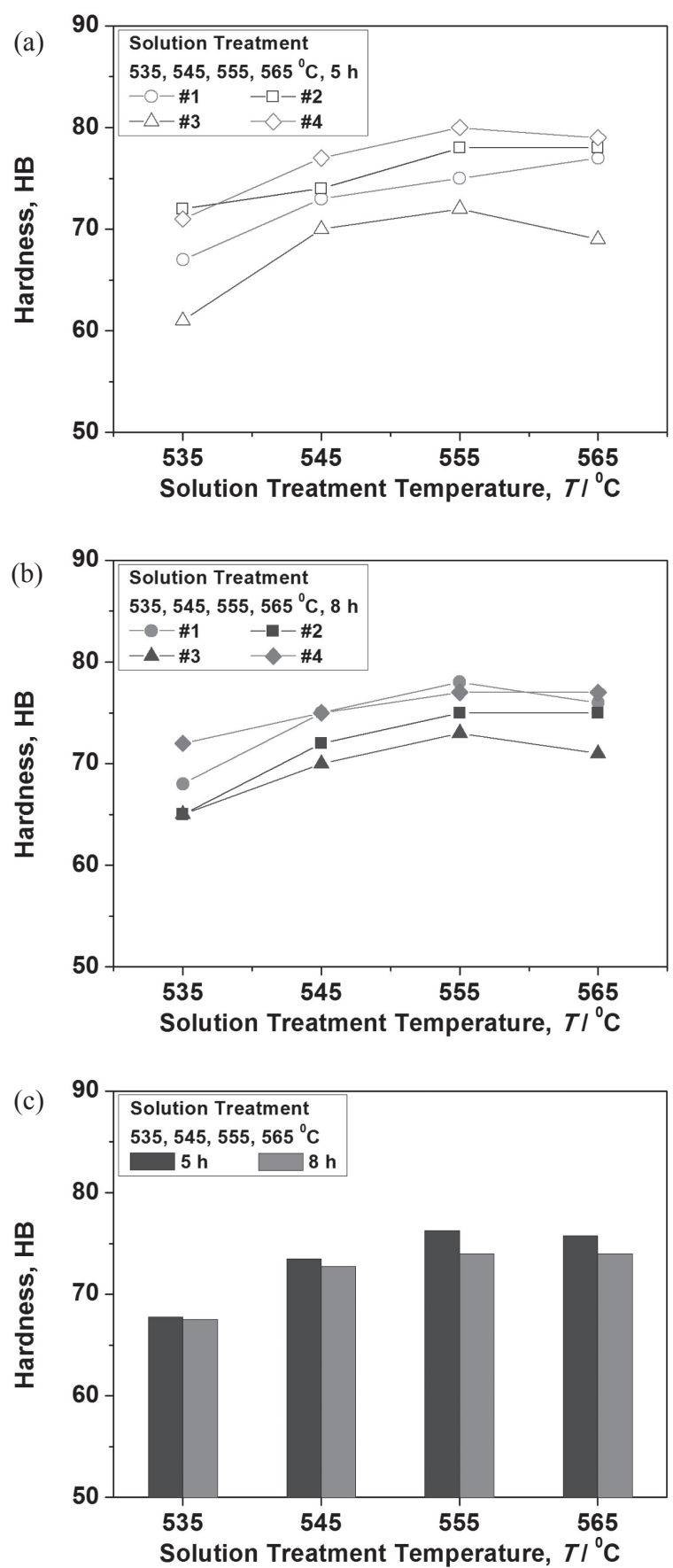

Fig. 10 Hardness of the Al-Mg-Si alloy after solution treatment, (a) $5 \mathrm{~h}$, (b) $8 \mathrm{~h}$ and (c) average values.

heat treatment time at the same heat treatment temperature. Microstructure analysis of the residual phases (Fig. 4) and the result of the lattice constant (Fig. 9) showed that the hardness increases with increasing temperature due to the solid solution hardening effect of the solubility increment for the matrix of solute atoms constituting the residual phase. On the other hand, above $565^{\circ} \mathrm{C}$, the hardness decreased because grain growth is more dominant over the increase in solubility caused by the increased temperature. To observe this, the grain size was analyzed according to the solution treatment conditions, as shown in Fig. 11.

Figure 11 shows the microstructures observed by OM after etching to determine the change in grains depending on the solution treatment conditions. Figure 12 presents the results

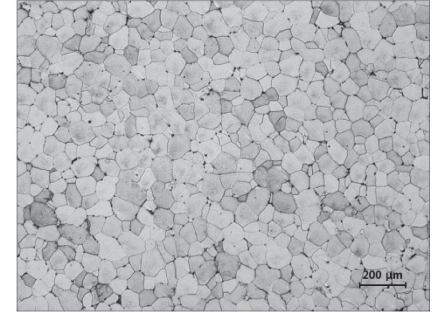

(a)

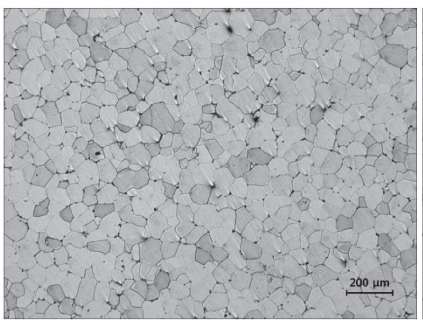

(c)

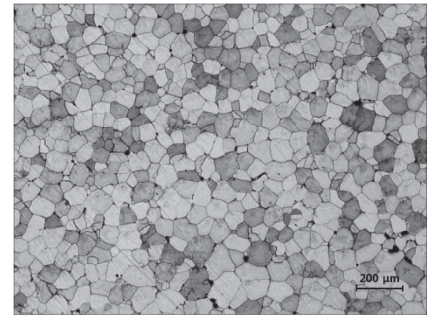

(e)

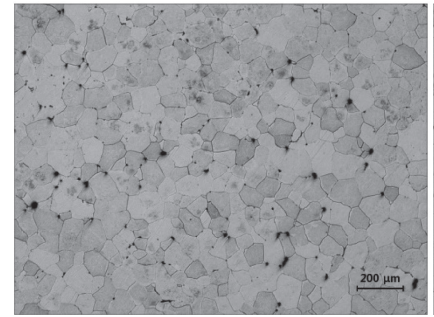

$(\mathrm{g})$

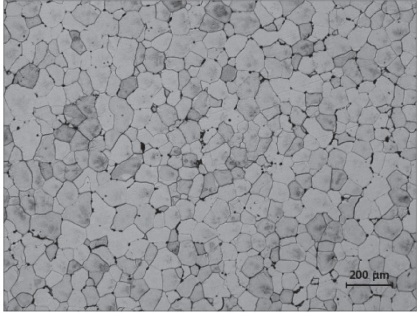

(b)

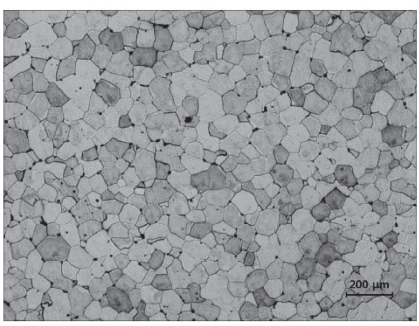

(d)

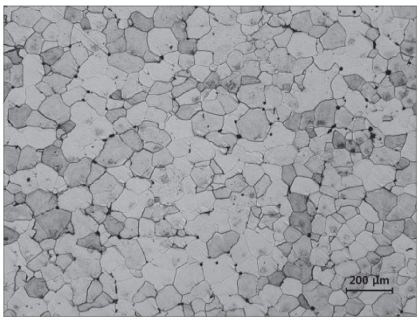

(f)

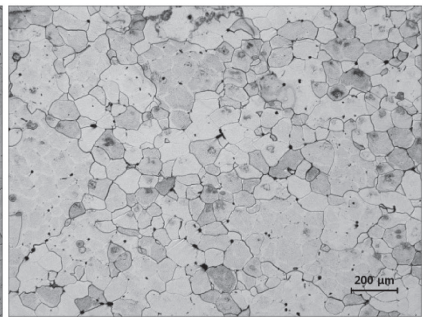

(h)
Fig. 11 Grain shapes of the $\mathrm{Al}-\mathrm{Mg}-\mathrm{Si}$ alloy after solution treatment: (a) $535^{\circ} \mathrm{C}, 5 \mathrm{~h}$; (b) $535^{\circ} \mathrm{C}, 8 \mathrm{~h}$; (c) $545^{\circ} \mathrm{C}, 5 \mathrm{~h}$; (d) $545^{\circ} \mathrm{C}, 8 \mathrm{~h}$; (e) $555^{\circ} \mathrm{C}$, $5 \mathrm{~h}$; (f) $555^{\circ} \mathrm{C}, 8 \mathrm{~h} ;(\mathrm{g}) 565^{\circ} \mathrm{C}, 5 \mathrm{~h}$; and (h) $565^{\circ} \mathrm{C}, 8 \mathrm{~h}$.

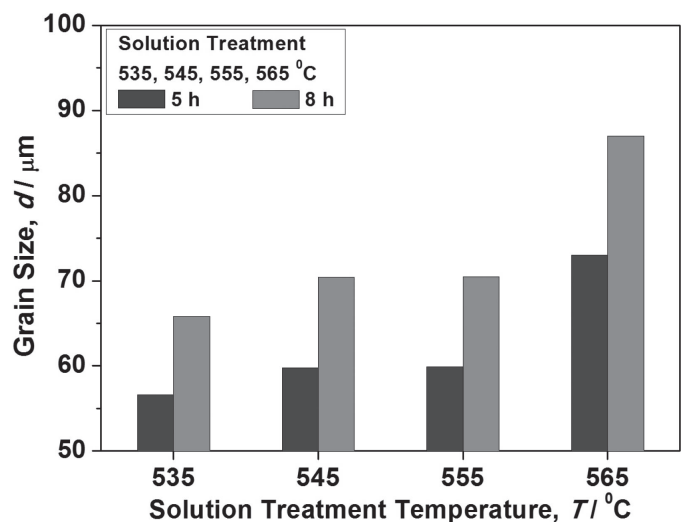

Fig. 12 Grain size measurements of the solution-treated Al-Mg-Si alloy. 


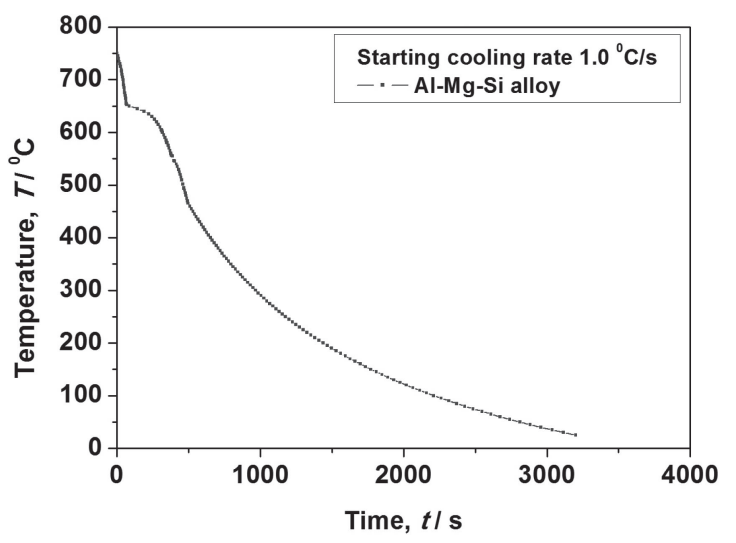

Fig. 13 Cooling curve of the Al-Mg-Si alloy.

of quantitative measurements of the grain size by line intercept method analysis of the image analyzer. Compared to the specimens that had been solution treated at 535 to $565^{\circ} \mathrm{C}$ and time for $5 \mathrm{~h}$, respectively, as the solution treatment temperature increased, the grain sizes increased gradually and coarse grains were locally observed. On the other hand, abrupt grain growth occurred at $565^{\circ} \mathrm{C}$ for $8 \mathrm{~h}$, as shown in Fig. 11(h). When the solution treatment temperature is increased for the same solution treatment time, the grain growth rate was not large enough up to $555^{\circ} \mathrm{C}$ but increased abruptly at $565^{\circ} \mathrm{C}$, as shown in Fig. 12 . In addition, grain growth accelerated with increasing solution treatment time at a given temperature. Therefore, the increase in solution treatment temperature and time has a role in the decrease in the residual phases and grain growth. The solid solution effect due to solute atoms is more dominant than the softening effect by grain growth up to $555^{\circ} \mathrm{C}$ for $\mathrm{Al}-\mathrm{Mg}-\mathrm{Si}$ alloys, which causes an increase in hardness with increasing solution treatment temperature. On the other hand, the hardness decreased at $565^{\circ} \mathrm{C}$, and with increasing solution treatment time from 5 to $8 \mathrm{~h}$ because the softening effect by the abrupt grain growth is dominant over solid solution strengthening. Figure 13 shows the results of solidification analysis of the Al-Mg-Si alloy with the composition in Table 1. The final solidification temperature (Ts) under equilibrium conditions was approximately $573^{\circ} \mathrm{C}$. Therefore, the solution treatment temperature of $565^{\circ} \mathrm{C}$ is close to the liquidus temperature, which results in abrupt grain growth. On the other hand, there are studies that the hardness tends to increase with increasing solution treatment time within a short time of $60 \mathrm{~min}^{26)}$ The time is not sufficiently long to change the residual phases and the grain size was small due to the short period. Therefore, the increase in solubility with time has a strong influence on the increase in hardness. From these results, to satisfy the mechanical properties required for the Al-Mg-Si alloy, the changes in the residual phase and grains depending on the solution-treated conditions need to be considered simultaneously.

\subsection{Tensile properties}

Tensile tests were carried out to measure the mechanical properties of the Al-Mg-Si alloy with the solution treatment conditions and the specimen locations of the automotive component, as shown in Fig. 14. Figures 14(a) and (b) show the yield and tensile strength, respectively; the yield and tensile strength increased at $555^{\circ} \mathrm{C}$ under the same time conditions, whereas the yield and tensile strength decreased when the solution treatment temperature was increased further to $565^{\circ} \mathrm{C}$. In addition, the elongation for the solution treated for $5 \mathrm{~h}$ increased to $555^{\circ} \mathrm{C}$ and then decreased, as shown in Figs. 14(c) and (d), which is the same tendency compared to the variation of yield and tensile strengths with the solid solution conditions. In contrast, when the solution treatment time was increased to $8 \mathrm{~h}$, the elongation decreased from $555^{\circ} \mathrm{C}$. Figure $14(\mathrm{e})$ shows the average tensile properties with each location of the specimen depending on the solution treatment conditions. As the solution treatment temperature was increased, the yield and tensile strength as well as elongation increased up to $555^{\circ} \mathrm{C}$, then decreased at $565^{\circ} \mathrm{C}$. These are consistent with the results of the lattice constant in Fig. 9 and the hardness properties in Fig. 10. In addition, the deviations of the tensile properties with each location of the specimen decreased with increasing solution treatment time at the same temperature, as shown in Figs. 14(a) $\sim(d)$, which is consistent with the hardness results in Fig. 10. These results were attributed to the uniform redissolution of precipitates and the solute atoms are diffused evenly into the matrix, as solution treatment time was increased. At the solution treatment temperature above $545^{\circ} \mathrm{C}$, the yield and tensile strength decreased with increasing time. On the other hand, at a solution treated temperature below $535^{\circ} \mathrm{C}$, the strength increased slightly, even though the solution treatment time increased. This suggests that the effect of solid solution hardening are larger than those of softening by grain growth at relatively low solution temperatures, even though the solution treatment time is increased from 5 to $8 \mathrm{~h}$. This is coincident with the research showing that the strength increases with time when the total solution treated time is less than $1 \mathrm{~h},{ }^{26)}$ and it is thought that solid solution hardening is larger than softening by grain growth even at a short solution treatment time. Therefore, the optimal temperature of solution treatment for the $\mathrm{Al}-\mathrm{Mg}-\mathrm{Si}$ alloys used in this study is $555^{\circ} \mathrm{C}$ with the greatest hardness and strength due to solid solution hardening. Moreover, the optimal time was $8 \mathrm{~h}$ with a decrease in the deviation of mechanical properties depending on the location of the specimens by the uniform heat treatment effects despite the decrease in strength. Continuous research will be needed to determine the optimal heat treatment conditions by considering the mechanical properties of the alloys depending on the aging temperature and time under the same solution treatment.

From the above results, in the case of establishing the optimal heat treatment conditions for wrought aluminum parts manufactured by casting, it was confirmed that hardness and tensile properties could be improved.

\section{Conclusions}

(1) The Al-Mg-Si alloy for automobile chassis parts consisted of $\beta-\mathrm{Al}_{5} \mathrm{FeSi}, \mathrm{Mg}_{2} \mathrm{Si}$ residual phases and $\mathrm{Al}$ matrix after solution treatment at $535 \sim 565^{\circ} \mathrm{C}$.

(2) As the solution temperature and time increased, the volume fraction of the residual phase decreased and the 

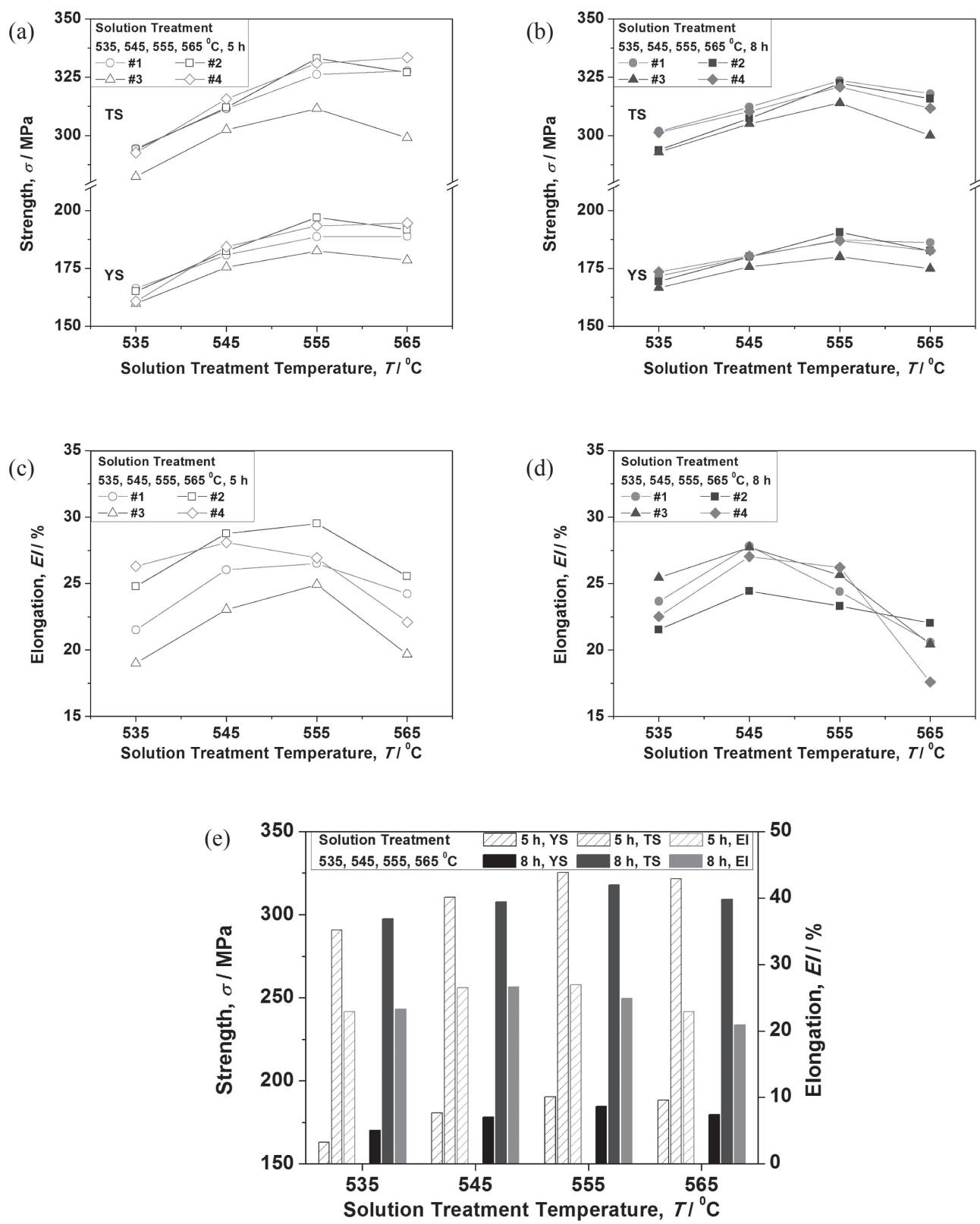

Fig. 14 Tensile properties of the Al-Mg-Si alloy after solution treatment: (a) strength, $5 \mathrm{~h}$; (b) strength, $8 \mathrm{~h}$; (c) elongation, $5 \mathrm{~h}$; (d) elongation, $8 \mathrm{~h}$; and (e) average values.

grain size increased gradually. In particular, the result of abrupt grain growth was observed at $565^{\circ} \mathrm{C}$.

(3) The hardness and tensile strength increased with increasing solution treatment temperature up to $555^{\circ} \mathrm{C}$ due to solid solution strengthening of the residual phase redissolution. On the other hand, when the solution was treated at $565^{\circ} \mathrm{C}$, the hardness and strength decreased because the softening effect by abrupt grain growth is more dominant than solid solution strengthening.

(4) As the solution treatment time increased at the same temperature, the solute atoms dissolve uniformly and the variation of mechanical properties by each location of the specimen tended to decrease owing to the uniform dissolution of solute atoms. In addition, the hardness, yield, and tensile strength decreased due to the softening effect by grain growth.

\section{Acknowledgments}

This study was supported by the Technology Innovation Program [10052437] funded By the Ministry of Trade, Industry \& Energy (MOTIE, Korea). Thanks are given for their financial support.

\section{REFERENCES}

1) B.R. Jin and C.Y. Jeong: Kor. J. Met. Mater. 54 (2016) 626-636.

2) M. Sato, M. Saito, K. Yasunaga, K. Kiyama and T. Idegomori: J. JILM 50 (2000) 121-127.

3) J. Shin, T. Kim, D.E. Kim, D. Kim and K. Kim: J. Alloys Compd. 698 (2017) 577-590.

4) W. Ma, B. Wang, L. Yang, X. Tang, W. Xiao and J. Zhou: Mater. Des. 88 (2015) 1119-1126.

5) J.H. Peng, X.L. Tang, J.T. He and D.Y. Xu: Trans. Nonferrous Met. 
Soc. China 21 (2011) 1950-1956.

6) H.R. Ammar, C. Moreaua, A.M. Samuel, F.H. Samuel and H.W. Doty: Mater. Sci. Eng. A 489 (2008) 426-438.

7) A. Meyveci, I. Karacana, U. Caligülüb and H. Durmus: J. Alloys Compd. 491 (2010) 278-283.

8) P. Li, S. Liu, L. Zhang and X. Liu: Mater. Des. 47 (2013) 522-528.

9) K.J. Kim and C.Y. Jeong: Mater. Trans. 57 (2016) 738-747.

10) C.Y. Jeong, C.S. Kang, J.I. Cho, I.H. Oh and Y.C. Kim: Int. J. Cast. Met. Res. 21 (2008) 193-197.

11) S.K. Tiwari, S. Soni, R.S. Rana and A. Singh: Mater. Today Proc. 4 (2017) 3458-3465.

12) C.Y. Jeong: Mater. Trans. 53 (2012) 234-239.

13) C.Y. Jeong: Mater. Trans. 54 (2013) 588-594.

14) K.S. Son, T.E. Park, J.S. Kim, S.M. Kim and D.G. Kim: Kor. J. Met. Mater. 48 (2010) 436-444.

15) K. Xia and G. Tausig: Mater. Sci. Eng. A 246 (1998) 1-10.

16) J. Dong, J.Z. Cui, Q.C. Le and G.M. Lu: Mater. Sci. Eng. A 345 (2003) 234-242.

17) S.W. Kim, D.Y. Kim, W.G. Kim and K.D. Woo: Mater. Sci. Eng. A 304
(2001) 721-726.

18) X.P. Ding, H. Cui, J.X. Zhang, H.X. Li, M.X. Guo, Z. Lin, L.Z. Zhuang and J.S. Zhang: Mater. Des. 65 (2015) 1229-1235.

19) M.X. Guo, J.Q. Du, C.H. Zheng, J.S. Zhang and L.Z. Zhuang: J. Alloys Compd. 778 (2019) 256-270.

20) Annual Book of ASTM Standards, Designation: ASTM E140-12b, 03.01, (2017) pp. 1-25.

21) Annual Book of ASTM Standards, Designation: ASTM E8M, 03.01, (2002) pp. 83-104.

22) J.C. Russ: The Image Processing Handbook, 5th ed., (CRC Press, America, 2006) p. 512.

23) H.Y. Kim, S.W. Han and H.M. Lee: J. Kor. Inst. Met. \& Mater. 43 (2005) 413-417.

24) J.G. Jung, J.S. Park, Y.S. Ha, Y.K. Lee, J.H. Jun, H.S. Kang and J.D. Lim: J. Kor. Inst. Met. \& Mater. 47 (2009) 223-227.

25) M. Rajabi, M. Vahidi, A. Simchi and P. Davami: Mater. Charact. 60 (2009) 1370-1381.

26) B. Li, Q. Pan, C. Chen, H. Wu and Z. Yin: J. Alloys Compd. 664 (2016) 553-564. 